\title{
Effects of High-intensity Statin Combined Telmisartan Versus Amlodipine on Glucose Metabolism in Hypertensive Atherosclerotic Cardiovascular Disease Patients With Impaired Fasting Glucose: a Randomized Multi-centre Trial
}

\section{Chan Joo Lee}

Yonsei University College of Medicine

Minji Kim

Yonsei University College of Medicine

Jung-Hoon Sung

CHA University School of Medicine

Tae-Soo Kang

Dankook University College of Medicine

\section{Sungha Park}

Yonsei University College of Medicine

\section{Sang-Hak Lee}

Yonsei University College of Medicine

Jong-Youn Kim

Yonsei University College of Medicine

Byeong-Keuk Kim ( $\sim$ kimbk@yuhs.ac)

Division of Cardiology, Severance Cardiovascular Hospital, Yonsei University College of Medicine, Seoul, Republic of Korea https://orcid.org/0000-0003-2493-066X

Original investigation

Keywords: Angiotensin-II-receptor blockers, calcium channel blocker, insulin resistance, statin, impaired fasting glucose, diabetes mellitus

Posted Date: October 1st, 2020

DOI: https://doi.org/10.21203/rs.3.rs-82618/v1

License: (c) (1) This work is licensed under a Creative Commons Attribution 4.0 International License. Read Full License 


\section{Abstract}

Background: Limited data are available regarding the role of angiotensin-II-receptor blockers (ARB) in the prevention of new-onset diabetes mellitus in patients with atherosclerotic cardiovascular disease (ASCVD) and hypertension requiring high-dose statin. This study aimed to compare the effects of telmisartan and amlodipine on glucose metabolism in hypertensive ASCVD patients with impaired fasting glucose (IFG) requiring high-intensity statin.

Methods: A total of 99 patients with hypertensive ASCVD with impaired fasting glucose $(100-125 \mathrm{mg} / \mathrm{dL}$ or $\mathrm{HbA} 1 \mathrm{c} 5.7 \%-6.4 \%)$ were randomly assigned to two groups [telmisartan-statin group $(n=48)$ and amlodipine-statin group $(n=51)]$ as the add-on therapy to high-dose rosuvastatin therapy $(20 \mathrm{mg})$. The primary endpoint was the value of the homeostatic model assessment for insulin resistance (HOMA-IR) at week 24 , and the secondary endpoint was the change in the glucose metabolism indices from baseline to week 24.

Results: The HOMA-IR at week 24 (2.4 [interquartile range, 1.8-3.8] versus 2.6 [1.7-3.7]; $P=0.809$ ) and changes in the HOMA-IR from baseline to week 24 (-7.0 [-29.0 to 21.0] versus -2.3 [ -53.3 to 27.3]; $P=$ 0.539) were not significantly different between the telmisartan-statin group and the amlodipine-statin group. However, the fasting glucose level at week 24 was significantly lower in the telmisartan-statin group $(107.7 \pm 13.4 \mathrm{mg} / \mathrm{dL})$ than in the amlodipine-statin group $(113.3 \pm 12.4 \mathrm{mg} / \mathrm{dL} ; \mathrm{P}=0.039)$ and significantly decreased from the baseline in the telmisartan-statin group $(-3.2 \% \pm 8.6 \%$ versus $3.8 \% \pm$ $13.2 \% ; P=0.003)$. The proportion of patients with IFG $(71.1 \%$ versus $89.6 \% ; P=0.047)$ or hemoglobin A1c level $>6.5 \%(4.2 \%$ versus $21.6 \% ; P=0.023)$ at week 24 was also significantly lower in the telmisartanstatin group than in the amlodipine-statin group.

Conclusion: Compared to amlodipine, telmisartan did not decrease the HOMA-IR; rather, an improvement in glucose metabolism was noted during the follow-up in hypertensive ASCVD patients with IFG requiring high-dose statin, suggesting the potential role of ARB for reducing risks owing to high-intensity statin.

Trial registration: clinicaltrials.gov, NCT03474562. Registered March 22, 2018,

https://clinicaltrials.gov/ct2/show/NCT03474562

\section{Introduction}

For the primary and secondary prevention of high cardiovascular risk of atherosclerotic cardiovascular disease (ASCVD), strict control of blood cholesterol using statins, is recommended, especially for lowering low-density lipoprotein cholesterol (LDL-C) [1]. Despite several beneficial effects of statin therapy, statin is associated with an increased risk of developing diabetes mellitus (DM) [2]. The metaanalyses of randomized clinical trials showed that statin therapy was associated with an increased risk of new-onset DM [3], and several experimental studies have reported that statins act on beta cells and reduce insulin secretion and inhibit glucose uptake in adipocytes and skeletal muscles, leading to insulin 
resistance and DM $[4,5]$. Particularly, these phenomena are more pronounced using high-intensity statins than moderate- or low-intensity statins, and statin-induced new-onset DM is more likely to occur in people with a high risk of diabetes [6, 7] Therefore, in patients with insulin resistance such as impaired fasting glucose (IFG) or elevated hemoglobin A1c ( $\mathrm{HbA1c})$, the risk of new-onset DM caused by high-intensity statins should be increased [8]. These patients at risk of new-onset DM requiring the management of hypertension and LDL-C could expect a decrease in insulin resistance using appropriate antihypertensive drugs. Among angiotensin II receptor blockers (ARB), telmisartan has been found to reduce insulin resistance by activating peroxisome proliferator-activated receptor gamma (PPARY) [9]. However, there are insufficient results on the changes in glucose metabolism, including insulin resistance, when highintensity statins and hypertension drugs are used in combination. Therefore, we aimed to compare the effects of telmisartan and amlodipine on glucose metabolism in hypertensive ASCVD patients with IFG requiring high-intensity rosuvastatin therapy.

\section{Methods}

\section{Study design}

This trial, the COMPROMISE (effect of high-dose rosuvastatin combined with telmisartan or amlodipine on glucose metabolism in atherosclerotic cardiovascular disease patients with impaired fasting glucose and hypertension) trial was a 24-week randomized, open-label, parallel, multicenter trial conducted at four sites in South Korea between October 2018 and May 2019. The local ethics review boards of each hospital approved the study protocol. The study was conducted in accordance with the principles of Declaration of Helsinki, and all patients provided written informed consent. After screening, participants were randomly segregated to the combination therapy with telmisartan and high-dose rosuvastatin (telmisartan-statin group) and the combination therapy with amlodipine and high-dose rosuvastatin (amlodipine-statin group) in a 1:1 ratio using pre-coded concealed envelopes generated by permutedblock randomization with a block size of two stratified using the study site.

The study design and flow are presented in Figure 1. All participants were initially treated with telmisartan $40 \mathrm{mg} /$ rosuvastatin $20 \mathrm{mg}$ once daily or amlodipine $5 \mathrm{mg} /$ rosuvastatin $20 \mathrm{mg}$ once daily for the first 12 weeks and were then up-titrated to telmisartan $80 \mathrm{mg} /$ rosuvastatin $20 \mathrm{mg}$ once daily or amlodipine 10 $\mathrm{mg} /$ rosuvastatin $20 \mathrm{mg}$ once daily for an additional 12 weeks if the participants did not meet blood pressure (BP) goals (mean sitting systolic BP/ diastolic BP of 140/90 mm Hg).

\section{Study population}

Patients aged 19-75 years who met the following conditions were enrolled: 1) patients with clinical ASCVD requiring high-intensity statin therapy (clinical ASCVD included acute coronary syndrome, history of myocardial infarction, stable or unstable angina, history of coronary revascularization, stroke or transient ischemic attack, peripheral arterial disease, or history of peripheral arterial revascularization) [1]; 2) patients who were taking antihypertensive drugs or with a systolic or diastolic BP of $>140 \mathrm{mmHg}$ or 
$>90 \mathrm{mmHg}$; and 3) patients who met the criteria for IFG (fasting plasma glucose of $100-125 \mathrm{mg} / \mathrm{dL}$ or $\mathrm{HbA2c}$ of $5.7 \%-6.4 \%)$ and has not been diagnosed with DM before.

The exclusion criteria were as follows: patients who were treated for secondary or malignant hypertension; uncontrollable DM with $\mathrm{HbA} 1 \mathrm{c} \geq 10 \%$; total cholesterol of $\geq 300 \mathrm{mg} / \mathrm{dL}$; fasting LDL-C of $\leq 70 \mathrm{mg} / \mathrm{dL}$ in statin-naïve patients; fasting triglyceride of $\geq 500 \mathrm{mg} / \mathrm{dL}$; history of muscular disease or rhabdomyolysis owing to statin use; hypersensitive to statin or ARBs; contraindications stated in the single-pill combination of telmisartan or rosuvastatin (severe renal disease, aspartate aminotransferase or alanine aminotransferase >three-fold upper normal limit or history of active liver disease, creatine phosphokinase >three-fold upper normal limit, or hyperkalemia); those who were participating in clinical trials of other investigational products; those who cannot discontinue all other treatments for hypertension or hyperlipidemia than the investigational products, concomitant medications, and supplements that can affect the therapeutic effects of hypertension and hyperlipidemia; and if the investigator considers participant to be ineligible to participate in the trial.

\section{Efficacy assessments}

The primary endpoint was the difference in the homeostatic model assessment for insulin resistance (HOMA-IR) at week 24. HOMA-IR was calculated using the formula: fasting insulin $(\mu \mathrm{U} / \mathrm{mL}) \times$ fasting glucose $(\mathrm{mg} / \mathrm{dL}) / 405$. The secondary endpoints were 1$)$ the changes from the baseline to the week 12 or 24 in the following variables: HOMA-IR, homeostasis model assessment of $\beta$-cell function (HOMA-B), fasting blood glucose, fasting insulin, $\mathrm{HbA} 1 \mathrm{c}$, lipid profiles (total cholesterol, triglyceride, LDL-cholesterol, and high-density lipoprotein-cholesterol (HDL-C)). HOMA-B was calculated using the formula: [fasting insulin $(\mu \mathrm{U} / \mathrm{mL}) \times 360$ ] / [fasting glucose $(\mathrm{mg} / \mathrm{dL})-63$ ] and 2$)$ the proportions of participants with fasting plasma glucose of $\geq 100 \mathrm{mg} / \mathrm{dL}$ or $\mathrm{HbA} 1 \mathrm{c}$ of $\geq 6.5 \%$ and the new-onset DM at week 24. New-onset DM was defined as the fasting plasma glucose of $\geq 125 \mathrm{mg} / \mathrm{dL}$ or $\mathrm{HbA} 1 \mathrm{c}$ of $\geq 6.5 \%$ at week 24 . The BP were measured during every visit to the out-patient clinic, and the adverse events and their severity and causal relationship were evaluated during the study period.

\section{Statistical analyses}

The sample size was estimated based on the HOMA-IR after treatment, as this was the primary endpoint. It was assumed that the baseline HOMA-IR was 2.6 (standard deviation (SD), 1.5), and it increased by $32 \%$ with rosuvastatin $20 \mathrm{mg}$ and decreased by $34 \%$ with telmisartan, but increased by $2 \%$ with amlodipine according to previous studies $[10,11]$. It was assumed that the HOMA-IR decreased to 2.54 and increased to 3.48 after a six-month treatment of telmisartan/rosuvastatin and amlodipine/rosuvastatin, respectively. An estimated sample size of 50 participants per treatment group would be required, considering a dropout rate of $20 \%$ and under the statistical conditions as follows: significance level $(\alpha), 0.05$; power, $0.80(\beta=0.2)$; and SD $(\sigma), 1.5$.

The baseline characteristics were compared between the two groups using the $\chi^{2}$ test for dichotomous variables or the $t$ test or Mann-Whitney test for continuous variables. The change in variables during the 
study period was investigated using the paired $t$-test or Wilcoxon signed-rank test according to the data distribution. The differences in the change in variables between the two groups were also compared using the $t$-test or Mann-Whitney test. The efficacy endpoints were analyzed using the full analysis set. The multivariate logistic regression models were used for estimating the association between the telmisartan use and new-onset DM. Model 1 included age, sex, BMI, use of beta-blocker, estimated glomerular filtration rate, and fasting plasma glucose as co-variates. Model 2 included HOMA-IR instead of fasting plasma glucose. A P-value of $<0.05$ was considered statistically significant. All analyses were performed using the software R (version 3.6.0 for Windows; The R Foundation for Statistical Computing, Austria).

\section{Results}

\section{Baseline characteristics of participants}

A total of 106 patients provided written consent to participate in the study; seven of them were screened out based on the exclusion criteria. Participants were randomly assigned to the telmisartan-statin group $(n=48)$ and amlodipine-statin group $(n=51)$. The mean age of participants was $60.1 \pm 8.8$ years, and $78 \%$ were men. The baseline characteristics of the enrolled participants are summarized in Table 1 . There were no significant differences between the groups.

\section{Changes in BP and lipid profiles}

The changes in BP and lipid profiles at the baseline and week 24 is presented in Table 2. At the baseline, systolic and diastolic BP did not differ between the two groups. At week 12, two participants in the amlodipine group and three in the telmisartan group received an increased dose of the drug because they did not reach the target BP. There was no difference in the systolic and diastolic BP at the end of the study (week 24). The changes in systolic/diastolic BP during the study period within each group did not show statistical significance, and there were no group-differences in the BP change.

For the lipid profile, there were no significant differences in lipid parameters at weeks 0 and 24 between the two groups (Table 2). The Supplementary Table 1 presented the change of lipid profile from the baseline to week 12. In both the groups, the changes in the total cholesterol, triglyceride, and LDL-C did not show statistical significance during the study period, and there was no statistical difference between the groups for each change except for the change in HDL-cholesterol levels in the amlodipine-statin group. The percentage change of HDL-cholesterol level from the baseline to week 24 did not differ between the two groups.

\section{Changes in parameters related to glucose metabolism}

The changes in the parameters related to glucose metabolism during the study period is presented in Table 3. The values of parameters at the baseline were similar between the groups. The HOMA-IR at week 24 , the primary endpoint of our study, was not significantly different between the telmisartan-statin and 
amlodipine-statin groups and the percentage changes in HOMA-IR from weeks 0 and 24 were also not significantly different for both the telmisartan-statin and amlodipine-statin groups (Table 3, Figure 2A). The change in HOMA-B from weeks 0-24 was maintained in the telmisartan-statin group but significantly decreased in the amlodipine-statin group (Table 3).

At week 24, the telmisartan-statin group showed a significantly lower level of fasting blood glucose than the amlodipine-statin group (Table 3, Figure 2B). Fasting blood glucose from the baseline to week 24 significantly decreased in the telmisartan-statin group but not in the amlodipine-statin group (Figure 2B). The percentage changes in fasting glucose from the baseline to week 24 was also significantly different between the two groups. The level of HbA1c and insulin at week 24 were not significantly different between the groups, and the changes in $\mathrm{HbA1c}$ and insulin from week 0-24 were also not significantly different in both the groups.

Figure 3 shows the proportion of participants with fasting plasma glucose of $\geq 100 \mathrm{mg} / \mathrm{dL}$ or HbA1c of $\geq 6.5 \%$ at weeks 0 and 24 . At week 24 , both the proportions of participants with fasting plasma glucose of $\geq 100 \mathrm{mg} / \mathrm{dL}(71.1 \%$ vs. $89.6 \%, \mathrm{P}=0.047$; Figure $3 \mathrm{~A})$ and $\mathrm{HbA} 1 \mathrm{c}$ of $\geq 6.5 \%$ ( $4.2 \%$ vs. $21.6 \%, \mathrm{P}=0.024$; Figure $3 \mathrm{~B}$ ) were significantly lower in the telmisartan-statin group than in the amlodipine-statin group. In addition, the proportion of the new-onset DM at week 24 was significantly lower in the telmisartan-statin group than in the amlodipine-statin group ( $12.5 \%$ vs. $31.4 \%, \mathrm{P}=0.044$; Figure $3 \mathrm{C}$ ).

In the multivariate logistic analyses (Table 4), the use of telmisartan was an independent protective factor for developing new-onset DM. High baseline fasting plasma glucose was the risk factor for developing new-onset DM, while HOMA-IR was not.

\section{Adverse events during study periods}

Of the 99 participants, 16 participants in the telmisartan-statin group and 19 participants in the amlodipine-statin group reported adverse events (Supplementary Table 2). There was no statistical difference between the two groups. None of the adverse events were serious adverse events. There were four cases in which the clinical trial drug was the likely cause of hypotension (one case), headache (one case), edema (one case), and dizziness (one case) in the amlodipine-statin group. There were four cases with facial flushing (one case), hypotension (two cases), and creatine phosphokinase rise (one case) in the telmisartan-statin group.

\section{Discussion}

To the best of our knowledge, our study is the first to demonstrate the usefulness of telmisartan in reducing the risk of statin-induced DM in ASCVD hypertensive patients requiring high-intensity statin. The main findings of this study were 1) for participants with IFG who had hypertension and ASCVD requiring high-intensity statin, both 24-week treatment of amlodipine and telmisartan did not significantly improve HOMA-IR. However, HOMA-B, an indicator of insulin secretion, was maintained in the telmisartan-statin group but significantly reduced in the amlodipine-statin group, suggesting the protective effect of 
telmisartan on beta-cell function; 2) fasting glucose tended to increase slightly at week 24 than at the baseline in the amlodipine-statin group, but it decreased significantly during the study period in the telmisartan-statin group, with a significantly lower value at week 24 in the telmisartan-statin group than in the amlodipine-statin group; and 3) the telmisartan-statin group showed a lower proportion of fasting plasma glucose of $\geq 100 \mathrm{mg} / \mathrm{dL}$ or $\mathrm{HbA} 1 \mathrm{c}$ of $\geq 6.5 \%$ and a lower rate of new-onset DM at 24 weeks than the amlodipine-statin group. In the multivariate analysis, the use of telmisartan was a significant protective factor for preventing new-onset DM at 24 weeks, demonstrating the beneficial role of telmisartan for ASCVD and IFG patients at-risk of DM and requiring high-intensity statin.

In several studies, statin has been shown to increase the risk of DM through various mechanisms: statin can affect beta-cell function, which is one of the possible mechanism of new-onset DM [12]. In statintreated beta cells, intracellular $\mathrm{Ca}^{2+}$ peaks induced by the uptake of glucose in beta cells are reduced, so a higher concentration of glucose is required for stimulating insulin secretion $[13,14]$. In addition, statin treatment affecting pancreatic islet beta cells reduces insulin secretion rate dose-dependently [15]. Another mechanism is that insulin resistance is increased by statins. Statin increases the expression of fatty acid synthesis gene, which leads to a higher amount of fatty acid content in the muscle [16]. The accumulation of fatty acid causes detrimental effect on insulin signaling in muscle cells [17]. Consistent with these results, HOMA-IR, an indicator of insulin resistance, showed a significant dose-dependent increase with rosuvastatin 10,20, and $40 \mathrm{mg}$ in hyperlipidemia patients with IFG [18]. Thus, the risk of developing DM could be increased by statins, but DM does not develop in all patients receiving statin. Patients with an increased insulin resistance have a higher risk of developing DM with statin medication $[3,6]$. It is strongly recommended not to discontinue statins in patients at a high risk of developing ASCVD because the protective effects of statins on cardiovascular disease outweigh the risk of diabetes [1]. However, considering the decrease in quality of life and the increase in medical expenses owing to DM, it is necessary to reduce the development of new-onset DM [19].

In ASCVD patients with hypertension and dyslipidemia, the choice of antihypertensive drugs would be a good way to lower the side effects of statin, especially the risks of new-onset DM. Among antihypertensive drugs, which are classified as first-line, beta-blocker, and thiazide-like diuretics are known to increase insulin resistance [20]. In contrast, renin-angiotensin-aldosterone system (RAAS) blockades, including ARB, can reduce the risk of new-onset DM through an important role in glucose homeostasis; angiotensin II negatively affects glucose uptake by inhibiting Glucose Transporter Type 4 translocation in the muscle and adipocytes, activates the inflammatory cytokine, and promotes the sympathetic nervous system, thereby increasing blood catecholamine levels, resulting in insulin resistance [21, 22]. Whereas calcium channel blockers, one of most common antihypertensive drug, have been reported to be associated with a higher incidence of DM than RAAS blockers in hypertensive patients [23].

Of the many ARBs, telmisartan has been reported to be more effective in lowering the risk of diabetes and differs from other ARBs in that it has a structural similarity to pioglitazone and can activate PPARy even at low concentrations [9]. A previous study showed that the combination of rosuvastatin with telmisartan decreased HOMA-IR in patients with IFG than irbesartan or olmesartan [10]. Telmisartan may be superior 
in preventing cardiovascular disease independently of the BP-lowering effect than amlodipine, a calcium channel blocker. Telmisartan attenuates $M C P$-1 gene expression in peripheral blood monocytes and increases PPAR-rgene expression than amlodipine and has a positive influence on glycemic control and insulin resistance [24].

Although there was no significant difference in HOMA-IR reduction between the treatments, 24-week telmisartan treatment preserved the level of HOMA-B, significantly reduced the level of fasting plasma glucose and the proportion of participants with fasting plasma glucose of $\geq 100 \mathrm{mg} / \mathrm{dL}$ or $\mathrm{HbA} 1 \mathrm{c}$ of $\geq 6.5 \%$, and increased the change in euglycemic status from IFG, which effectively lowered the incidence of new-onset DM in patients receiving high-intensity statin than the 24-week amlodipine treatment. Prior studies had examined the effects of telmisartan in patients with insulin resistance regardless of the use of statin and evaluated the changes in metabolic parameters using a combination of telmisartan and a moderate dose of rosuvastatin without comparing with amlodipine $[10,25,26]$. Thus, our study was the first to investigate the effects of telmisartan versus amlodipine on glucose homeostasis in hypertensive ASCVD patients with high-dose and high-intensity statin treatment.

Telmisartan showed a tendency to improve insulin resistance and beta-cell function in patients with insulin resistance compared to a placebo [25]. In contrast, the numerical improvement in HOMA-IR was not shown in our study. This is probably because the average baseline HOMA-IR was 3.8 in the previous study, but the baseline HOMA-IR was lower in our study. Therefore, the reduction effect by telmisartan might not be well observed. Generally, telmisartan has a favorable effect on glucose metabolism, but there are also reports indicating that telmisartan show a neutral effect on HOMA-IR [27]. One of the novelties of our study was that telmisartan showed no changes in HOMA-B compared to amlodipine. Low HOMA-B is associated with a high risk of diabetes [28], and this is the first human study to confirm that telmisartan can prevent the statin-induced deterioration of beta-cell function.

There are some limitations of this study. First, this study was not double-blinded and not placebocontrolled. Second, because this study targeted patients with clinical ASCVD, most of these patients had hypertension, and the antihypertensive drug previously administered could have affected the metabolic parameters. Hence, a wash-out period should be considered after discontinuation of the antihypertensive drugs. However, the setting of wash-out period was impossible for patients with clinical ASCVD. Third, this study did not target statin-naïve patients. Therefore, it is possible that HOMA-IR was not significantly changed by rosuvastatin at the end of the study compared to the baseline. Finally, the weight changes or lifestyle modification might affect glucose metabolism even with short-term observation, but these were not analyzed.

\section{Conclusion}

In summary, the telmisartan-rosuvastatin combination could not significantly improve insulin resistance, but preserved insulin secretion, improved fasting blood glucose, and reduced the risks of new-onset DM than the amlodipine-rosuvastatin combination in hypertensive ASCVD patients with IFG. 


\section{List Of Abbreviations}

ASCVD, atherosclerotic cardiovascular disease; LDL-C, low-density lipoprotein cholesterol; HDL-C, highdensity lipoprotein cholesterol; DM, diabetes mellitus; HbA1c, hemoglobin A1c; IFG, impaired fasting glucose; ARB, angiotensin II receptor blockers; PPARy, peroxisome proliferator-activated receptor gamma; HOMA-IR, homeostatic model assessment for insulin resistance; BP, blood pressure; SD, standard deviation; RAAS, renin-angiotensin-aldosterone system.

\section{Declarations}

\section{Acknowledgements}

We would like to thank Editage (www.editage.co.kr) for English language editing.

\section{Authors' contributions}

All authors are involved in the planning and execution of the COMPROMISE trial. CJL analyzed the data and wrote the manuscript. MK assisted in study design. J-HS, T-SK, J-YK and B-KK carried out subject recruitment. J-YK and B-KK are responsible for drafting this article and preparing the figures, tables, and additional files. The other authors critically reviewed the entire article. All authors read and approved the final manuscript.

\section{Funding}

This study was funded by Yuhan Corporation (Seoul, Korea).

\section{Conflict of Interest}

None

\section{Ethics approval and consent to participate}

The ethics review boards of the Yonsei University College of Medicine (4-2017-1239) and each hospital approved the study protocol. The study was conducted in accordance with the principles of Declaration of Helsinki, and all patients provided written informed consent.

\section{Consent for publication}

Not applicable.

\section{Availability of data and materials}

Not applicable.

\section{References}


1. Grundy SM, Stone NJ, Bailey AL, Beam C, Birtcher KK, Blumenthal RS, et al. 2018 AHA/ACC/AACVPR/AAPA/ABC/ACPM/ADA/AGS/APhA/ASPC/NLA/PCNA Guideline on the Management of Blood Cholesterol: A Report of the American College of Cardiology/American Heart Association Task Force on Clinical Practice Guidelines. J Am Coll Cardiol. 2019;73(24):e285-e350.

2. Violi F, Calvieri C, Ferro D, Pignatelli P. Statins as antithrombotic drugs. Circulation. 2013;127(2):2517.

3. Sattar N, Preiss D, Murray HM, Welsh P, Buckley BM, de Craen AJ, et al. Statins and risk of incident diabetes: a collaborative meta-analysis of randomised statin trials. Lancet. 2010;375(9716):735-42.

4. Carmena R, Betteridge DJ. Diabetogenic Action of Statins: Mechanisms. Curr Atheroscler Rep. 2019;21(6):23.

5. Han KH. Functional Implications of HMG-CoA Reductase Inhibition on Glucose Metabolism. Korean Circ J. 2018;48(11):951-63.

6. Preiss D, Seshasai SR, Welsh P, Murphy SA, Ho JE, Waters DD, et al. Risk of incident diabetes with intensive-dose compared with moderate-dose statin therapy: a meta-analysis. Jama. 2011;305(24):2556-64.

7. Ridker PM, Pradhan A, MacFadyen JG, Libby P, Glynn RJ. Cardiovascular benefits and diabetes risks of statin therapy in primary prevention: an analysis from the JUPITER trial. Lancet. 2012;380(9841):565-71.

8. Waters DD, Ho JE, Boekholdt SM, DeMicco DA, Kastelein JJ, Messig M, et al. Cardiovascular event reduction versus new-onset diabetes during atorvastatin therapy: effect of baseline risk factors for diabetes. J Am Coll Cardiol. 2013;61(2):148-52.

9. Benson SC, Pershadsingh HA, Ho Cl, Chittiboyina A, Desai P, Pravenec M, et al. Identification of telmisartan as a unique angiotensin II receptor antagonist with selective PPARgamma-modulating activity. Hypertension. 2004;43(5):993-1002.

10. Rizos CV, Milionis HJ, Kostapanos MS, Florentin M, Kostara CE, Elisaf MS, et al. Effects of rosuvastatin combined with olmesartan, irbesartan, or telmisartan on indices of glucose metabolism in Greek adults with impaired fasting glucose, hypertension, and mixed hyperlipidemia: a 24-week, randomized, open-label, prospective study. Clin Ther. 2010;32(3):492-505.

11. Shimabukuro $M$, Tanaka $H$, Shimabukuro T. Effects of telmisartan on fat distribution in individuals with the metabolic syndrome. J Hypertens. 2007;25(4):841-8.

12. Yada T, Nakata M, Shiraishi T, Kakei M. Inhibition by simvastatin, but not pravastatin, of glucoseinduced cytosolic Ca2+ signalling and insulin secretion due to blockade of L-type Ca2+ channels in rat islet beta-cells. Br J Pharmacol. 1999;126(5):1205-13.

13. Zhao W, Zhao SP. Different effects of statins on induction of diabetes mellitus: an experimental study. Drug Des Devel Ther. 2015;9:6211-23.

14. Salunkhe VA, Mollet IG, Ofori JK, Malm HA, Esguerra JL, Reinbothe TM, et al. Dual Effect of Rosuvastatin on Glucose Homeostasis Through Improved Insulin Sensitivity and Reduced Insulin Secretion. EBioMedicine. 2016;10:185-94. 
15. Salunkhe VA, Elvstam O, Eliasson L, Wendt A. Rosuvastatin Treatment Affects Both Basal and Glucose-Induced Insulin Secretion in INS-1 832/13 Cells. PLoS One. 2016;11(3):e0151592.

16. Seshadri S, Rapaka N, Prajapati B, Mandaliya D, Patel S, Muggalla CS, et al. Statins exacerbate glucose intolerance and hyperglycemia in a high sucrose fed rodent model. Sci Rep. 2019;9(1):8825.

17. Martins AR, Nachbar RT, Gorjao R, Vinolo MA, Festuccia WT, Lambertucci RH, et al. Mechanisms underlying skeletal muscle insulin resistance induced by fatty acids: importance of the mitochondrial function. Lipids Health Dis. 2012;11:30.

18. Kostapanos MS, Milionis HJ, Agouridis AD, Rizos CV, Elisaf MS. Rosuvastatin treatment is associated with an increase in insulin resistance in hyperlipidaemic patients with impaired fasting glucose. Int J Clin Pract. 2009;63(9):1308-13.

19. Bommer C, Heesemann E, Sagalova V, Manne-Goehler J, Atun R, Bärnighausen T, et al. The global economic burden of diabetes in adults aged 20-79 years: a cost-of-illness study. Lancet Diabetes Endocrinol. 2017;5(6):423-30.

20. Stump CS, Hamilton MT, Sowers JR. Effect of antihypertensive agents on the development of type 2 diabetes mellitus. Mayo Clin Proc. 2006;81(6):796-806.

21. Velloso LA, Folli F, Sun XJ, White MF, Saad MJ, Kahn CR. Cross-talk between the insulin and angiotensin signaling systems. Proc Natl Acad Sci U S A. 1996;93(22):12490-5.

22. Reaven GM, Lithell H, Landsberg L. Hypertension and associated metabolic abnormalities-the role of insulin resistance and the sympathoadrenal system. N Engl J Med. 1996;334(6):374-81.

23. Noto H, Goto A, Tsujimoto T, Noda M. Effect of calcium channel blockers on incidence of diabetes: a meta-analysis. Diabetes Metab Syndr Obes. 2013;6:257-61.

24. Marketou ME, Kontaraki JE, Tsakountakis NA, Zacharis EA, Kochiadakis GE, Arfanakis DA, et al. Differential effect of telmisartan and amlodipine on monocyte chemoattractant protein-1 and peroxisome proliferator-activated receptor-gamma gene expression in peripheral monocytes in patients with essential hypertension. Am J Cardiol. 2011;107(1):59-63.

25. Nagel JM, Tietz AB, Göke B, Parhofer KG. The effect of telmisartan on glucose and lipid metabolism in nondiabetic, insulin-resistant subjects. Metabolism. 2006;55(9):1149-54.

26. Mori Y, Tanaka T, Matsuura K, Yokoyama J, Utsunomiya K. Influence of telmisartan on insulin response after glucose loading in obese patients with hypertension: ARB trial of hypertension in obese patients with hyperinsulinemia assessed by oral glucose tolerance test (ATHLETE). Adv Ther. 2011;28(8):698-706.

27. Bahadir O, Uzunlulu M, Oguz A, Bahadir MA. Effects of telmisartan and losartan on insulin resistance in hypertensive patients with metabolic syndrome. Hypertens Res. 2007;30(1):49-53.

28. Song Y, Manson JE, Tinker L, Howard BV, Kuller LH, Nathan L, et al. Insulin sensitivity and insulin secretion determined by homeostasis model assessment and risk of diabetes in a multiethnic cohort of women: the Women's Health Initiative Observational Study. Diabetes Care. 2007;30(7):1747-52.

\section{Tables}


Table 1. Baseline characteristics

\begin{tabular}{|c|c|c|c|}
\hline Variables & $\begin{array}{l}\text { Telmisartan- } \\
\text { statin }\end{array}$ & $\begin{array}{l}\text { Amlodipine- } \\
\text { statin }\end{array}$ & $\begin{array}{l}\text { P- } \\
\text { value }\end{array}$ \\
\hline & $(n=48)$ & $(n=51)$ & \\
\hline Age, years & $61.0 \pm 8.8$ & $59.3 \pm 8.8$ & 0.347 \\
\hline Male, n (\%) & $39(81.2)$ & $38(74.5)$ & 0.573 \\
\hline Height, cm & $166.8 \pm 8.1$ & $166.2 \pm 8.4$ & 0.712 \\
\hline Weight, cm & $71.7 \pm 10.3$ & $72.1 \pm 12.1$ & 0.887 \\
\hline Body mass index, $\mathrm{kg} / \mathrm{m}^{2}$ & $25.7 \pm 2.9$ & $26.0 \pm 3.1$ & 0.678 \\
\hline Coronary artery diseases, $\mathrm{n}(\%)$ & $48(100.0)$ & $51(100.0)$ & - \\
\hline Acute coronary syndrome, n (\%) & $32(66.7)$ & $41(80.4)$ & 0.186 \\
\hline Coronary revascularization, n (\%) & $22(45.8)$ & $28(54.9)$ & 0.483 \\
\hline Stroke or transient ischemic attack, n (\%) & $2(4.2)$ & $2(3.9)$ & 0.999 \\
\hline $\begin{array}{l}\text { Peripheral arterial disease or history of peripheral arterial } \\
\text { revascularization , } \mathrm{n}(\%)\end{array}$ & $0(0.0)$ & $2(3.9)$ & 0.502 \\
\hline Estimated glomerular filtration rate, $\mathrm{mL} / \mathrm{min} / 1.73 \mathrm{~m}^{2}$ & $87.8 \pm 17.8$ & $85.8 \pm 14.7$ & 0.542 \\
\hline AST, IU/L & $23.8 \pm 8.1$ & $25.5 \pm 7.8$ & 0.291 \\
\hline ALT, IU/L & $27.7 \pm 14.7$ & $30.0 \pm 13.8$ & 0.422 \\
\hline Creatine phosphokinase, $\mathrm{U} / \mathrm{L}$ & $117.9 \pm 47.6$ & $\begin{array}{l}129.7 \pm \\
69.5\end{array}$ & 0.325 \\
\hline \multicolumn{4}{|l|}{ Combined medication } \\
\hline Aspirin or clopidogrel & $48(100)$ & $51(100)$ & - \\
\hline Beta-blockade & $39(81.2)$ & $44(86.3)$ & 0.685 \\
\hline Anti-anginal drugs & $24(50.0)$ & $24(47.1)$ & 0.927 \\
\hline \multicolumn{4}{|c|}{ Data are presented as mean \pm standard deviation or number (\%). } \\
\hline \multicolumn{4}{|c|}{$\begin{array}{l}\text { IFG, impaired fasting glucose; IGT, impaired glucose tolerance; PAD, peripheral arterial disease; ALT, } \\
\text { alanine aminotransferase; AST, aspartate aminotransaminase. }\end{array}$} \\
\hline
\end{tabular}

Table 2. Blood pressure and lipid profile changes 


\begin{tabular}{|c|c|c|c|}
\hline group & $\begin{array}{l}\text { Telmisartan-statin } \\
\text { group }\end{array}$ & $\begin{array}{l}\text { Amlodipine-statin } \\
\text { group }\end{array}$ & $\begin{array}{l}\mathrm{P} \text { - } \\
\text { value }\end{array}$ \\
\hline & $(n=48)$ & $(n=51)$ & \\
\hline Office systolic BP at week 0 & $130.5 \pm 12.1$ & $130.6 \pm 15.2$ & 0.990 \\
\hline Office systolic BP at week 24 & $127.1 \pm 11.2$ & $129.4 \pm 13.0$ & 0.351 \\
\hline Change from week 0 and 24 & $-2.9 \pm 14.3$ & $-1.7 \pm 14.1$ & 0.675 \\
\hline P-value for paired T-test & 0.177 & 0.408 & \\
\hline Office diastolic BP at week 0 & $80.2 \pm 9.2$ & $78.8 \pm 9.8$ & 0.473 \\
\hline Office diastolic BP at week 24 & $80.6 \pm 7.5$ & $81.7 \pm 8.4$ & 0.497 \\
\hline Change from week 0 and 24 & $0.6 \pm 10.2$ & $2.6 \pm 9.1$ & 0.329 \\
\hline P-value for paired T-test & 0.593 & 0.057 & \\
\hline $\begin{array}{l}\text { Total cholesterol at week } 0 \text {, } \\
\mathrm{mg} / \mathrm{dL}\end{array}$ & $141.7 \pm 21.7$ & $142.3 \pm 22.6$ & 0.908 \\
\hline $\begin{array}{l}\text { Total cholesterol at week } 24 \text {, } \\
\mathrm{mg} / \mathrm{dL}\end{array}$ & $141.4 \pm 29.8$ & $146.6 \pm 32.2$ & 0.425 \\
\hline$\%$ change & $0.1 \pm 21.2$ & $3.7 \pm 22.6$ & 0.436 \\
\hline P-value for paired T-test & 0.565 & 0.468 & \\
\hline Triglyceride at week $0, \mathrm{mg} / \mathrm{dL}$ & $145.0 \pm 83.1$ & $139.6 \pm 61.9$ & 0.718 \\
\hline Triglyceride at week $24, \mathrm{mg} / \mathrm{dL}$ & $144.5 \pm 68.7$ & $141.8 \pm 66.3$ & 0.845 \\
\hline$\%$ change & $8.0 \pm 45.9$ & $6.9 \pm 41.9$ & 0.906 \\
\hline P-value for paired T-test & 0.673 & 0.968 & \\
\hline HDL-cholesterol at week $0, \mathrm{mg} / \mathrm{dL}$ & $48.1 \pm 10.1$ & $47.2 \pm 10.3$ & 0.671 \\
\hline $\begin{array}{l}\text { HDL-cholesterol at week } 24 \text {, } \\
\mathrm{mg} / \mathrm{dL}\end{array}$ & $47.9 \pm 9.8$ & $50.1 \pm 12.0$ & 0.331 \\
\hline$\%$ change & $0.7 \pm 14.3$ & $6.5 \pm 15.4$ & 0.061 \\
\hline P-value for paired T-test & 0.890 & 0.008 & \\
\hline LDL-cholesterol at week $0, \mathrm{mg} / \mathrm{dL}$ & $71.6 \pm 21.7$ & $71.9 \pm 17.8$ & 0.937 \\
\hline $\begin{array}{l}\text { LDL-cholesterol at week } 24 \text {, } \\
\mathrm{mg} / \mathrm{dL}\end{array}$ & $70.8 \pm 23.8$ & $73.5 \pm 30.6$ & 0.635 \\
\hline$\%$ change & $-0.3 \pm 33.6$ & $3.7 \pm 38.4$ & 0.596 \\
\hline P-value for paired T-test & 0.443 & 0.764 & \\
\hline
\end{tabular}


BP, blood pressure; HDL, high density lipoprotein; LDL, low density lipoprotein; SBP, systolic blood pressure.

Table 3. The changes of parameters related with glucose metabolism 


\begin{tabular}{|c|c|c|c|}
\hline & $\begin{array}{l}\text { Telmisartan-statin } \\
\text { group }\end{array}$ & $\begin{array}{l}\text { Amlodipine-statin } \\
\text { group }\end{array}$ & $\begin{array}{l}P \text { - } \\
\text { value }\end{array}$ \\
\hline & $(\mathrm{N}=48)$ & $(\mathrm{N}=51)$ & \\
\hline HOMA-IR at week 0 & 2.8 (1.8 to 4.6$)$ & 2.8 (1.7 to 7.2 ) & 0.800 \\
\hline HOMA-IR at week 24 & 2.4 (1.8 to 3.8$)$ & 2.7 (1.7 to 3.7$)$ & 0.809 \\
\hline$\%$ change & $-7.0(-28.0$ to 21.3$)$ & $-5.5(-53.3$ to 27.3$)$ & 0.539 \\
\hline $\begin{array}{l}\text { P-value for Wilcoxon Signed-Rank } \\
\text { Test }\end{array}$ & 0.407 & 0.087 & \\
\hline HOMA-B at week 0 & 76.4 (46.8 to 122.9$)$ & 86.8 (48.7 to 211.3 ) & 0.315 \\
\hline HOMA-B at week 24 & 74.1 (54.5 to 103.6$)$ & $63.6(45.4$ to 102.9$)$ & 0.252 \\
\hline$\%$ change & $-6.0(-23.3$ to 26.9$)$ & $-19.8(-52.7$ to 3.3$)$ & 0.040 \\
\hline $\begin{array}{l}\text { P-value for Wilcoxon Signed-Rank } \\
\text { Test }\end{array}$ & 0.467 & $<0.001$ & \\
\hline Fasting glucose at week $0, \mathrm{mg} / \mathrm{dL}$ & $111.2 \pm 10.2$ & $110.0 \pm 10.0$ & 0.566 \\
\hline Fasting glucose at week $24, \mathrm{mg} / \mathrm{dL}$ & $107.7 \pm 13.4$ & $113.3 \pm 12.4$ & 0.039 \\
\hline$\%$ change & $-3.2 \pm 8.6$ & $3.8 \pm 13.2$ & 0.003 \\
\hline P-value for paired T-test & 0.016 & 0.075 & \\
\hline $\mathrm{HbA} 1 \mathrm{c}$ at week $0, \%$ & $6.0 \pm 0.3$ & $6.0 \pm 0.6$ & 0.443 \\
\hline $\mathrm{HbA} 1 \mathrm{c}$ at week $24, \%$ & $6.0 \pm 0.3$ & $6.0 \pm 0.4$ & 0.498 \\
\hline$\%$ change & $0.1 \pm 3.2$ & $0.5 \pm 4.7$ & 0.625 \\
\hline P-value for paired T-test & 0.876 & 0.469 & \\
\hline Insulin at week $0, \mathrm{mIU} / \mathrm{L}$ & 9.5 (6.4 to 15.9$)$ & $10.2(6.6$ to 27.9$)$ & 0.361 \\
\hline Insulin at week $24, \mathrm{mlU} / \mathrm{L}$ & $9.2(7.2$ to 13.8$)$ & $9.7(5.9$ to 13.8$)$ & 0.750 \\
\hline$\%$ change & $-3.6(-31.6$ to 19.5$)$ & $-6.8(-52.2$ to 21.1$)$ & 0.595 \\
\hline $\begin{array}{l}\text { P-value for Wilcoxon Signed-Rank } \\
\text { Test }\end{array}$ & 0.221 & 0.082 & \\
\hline \multicolumn{4}{|c|}{ Data are presented as mean \pm standard deviation or median (interquartile range). } \\
\hline $\begin{array}{l}\text { HOMA-B, homeostatic model asses } \\
\text { assessment for insulin resistance. }\end{array}$ & t for beta cell functi & MA-IR, homeostatic $n$ & \\
\hline
\end{tabular}

Table 4. Independent predictors for developing the new-onset diabetes mellitus 


\begin{tabular}{|llll|}
\hline Variables & OR & $95 \% \mathrm{Cl}$ & P value \\
\hline Model 1 & & & \\
\hline Use of telmisartan (ref=amlodipine) & 0.18 & $0.05-0.61$ & 0.009 \\
\hline Age & 0.97 & $0.90-1.05$ & 0.511 \\
\hline Sex (ref=male) & 0.15 & $0.02-0.86$ & 0.060 \\
\hline BMI at baseline & 0.89 & $0.70-1.12$ & 0.337 \\
\hline Use of beta-blockade (ref=non-user) & 2.29 & $0.49-16.76$ & 0.338 \\
\hline Estimated GFR at baseline & 0.99 & $0.99-1.08$ & 0.112 \\
\hline FPG at baseline & 1.12 & $1.05-1.21$ & $<0.001$ \\
\hline Model 2 & & & \\
\hline Use of telmisartan (ref=amlodipine) & 0.27 & $0.08-0.79$ & 0.022 \\
\hline Age & 0.99 & $0.93-1.07$ & 0.874 \\
\hline Sex (ref=male) & 0.24 & $0.03-1.09$ & 0.097 \\
\hline BMI at baseline & 0.92 & $0.74-1.13$ & 0.420 \\
\hline Use of beta-blockade (ref=non-user) & 2.16 & $0.48-15.58$ & 0.363 \\
\hline Estimated GFR at baseline & 1.01 & $0.97-1.05$ & 0.468 \\
\hline HOMA-IR at baseline & 1.02 & $0.99-1.06$ & 0.153 \\
\hline FPG, fasting plasma glucose; GFR, glomerular filtration rate; HOMA-IR, homeostatic model \\
\hline assessment for insulin resistance. & & & \\
\hline
\end{tabular}

\section{Figures}




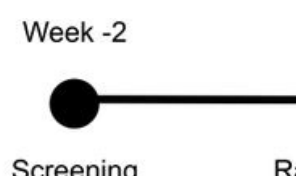

Screening

Clinical ASCVD patients with IFG and hypertension

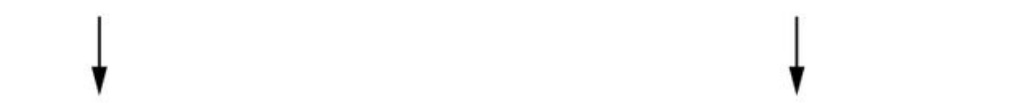

Telmisartan $80 \mathrm{mg}+$ Rosuvastatin $20 \mathrm{mg}$

Telmisartan $40 \mathrm{mg}+$ Rosuvastatin $20 \mathrm{mg}$

\section{Amlodipine $5 \mathrm{mg}+$ Rosuvastatin $20 \mathrm{mg}$}

Amlodipine $10 \mathrm{mg}+$ Rosuvastatin $20 \mathrm{mg}$

\section{Figure 1}

Study design and flow. BP, blood pressure; IFG, impaired fasting glucose.

(A) Telmisartan-statin

$$
P=0.407
$$

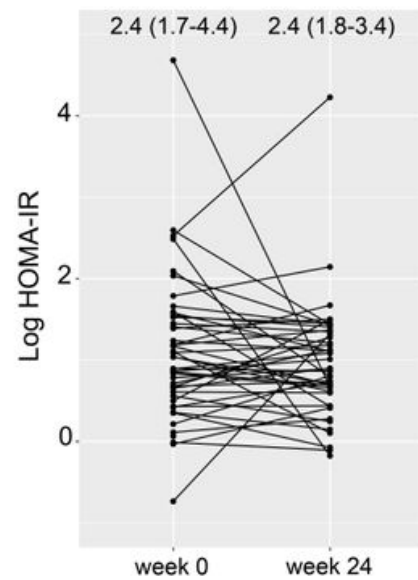

Amlodipine-statin

$$
P=0.087
$$

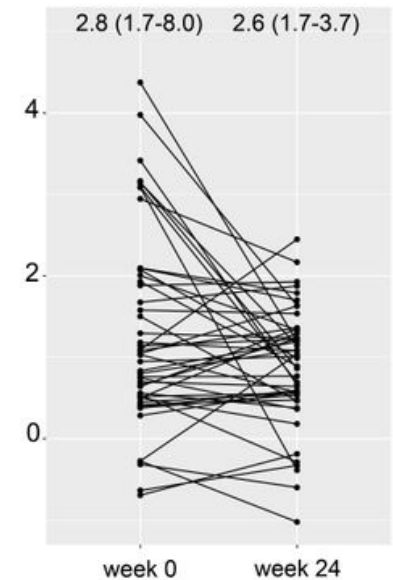

(B)

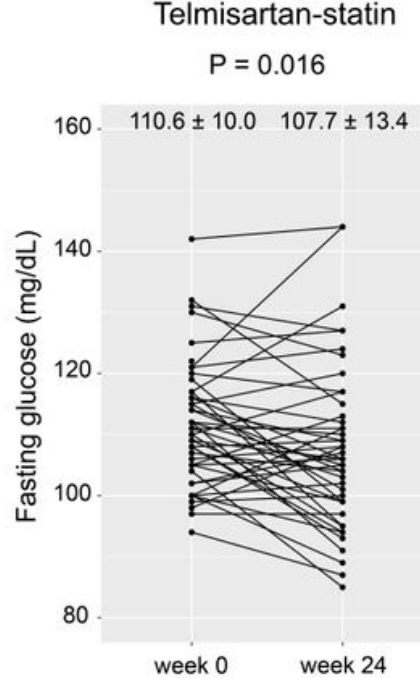

Amlodipine-statin

$$
P=0.075
$$

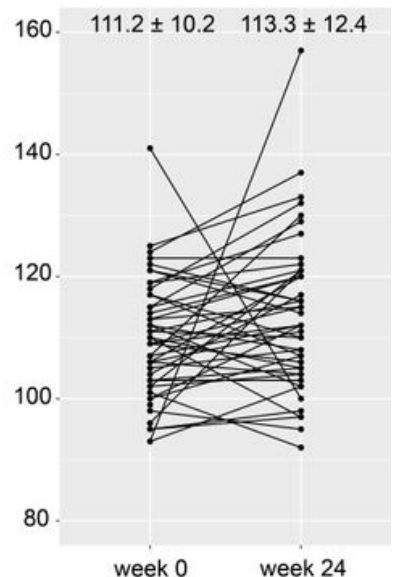

\section{Figure 2}

The change of HOMA-IR (A) and fasting glucose level (B) from week 0 to week 24 in each group. Values on the figure were median (interquartile range) or mean \pm standard deviation. $P$ values for Wilcoxon Signed Rank test (A) and paired T-test (B). 

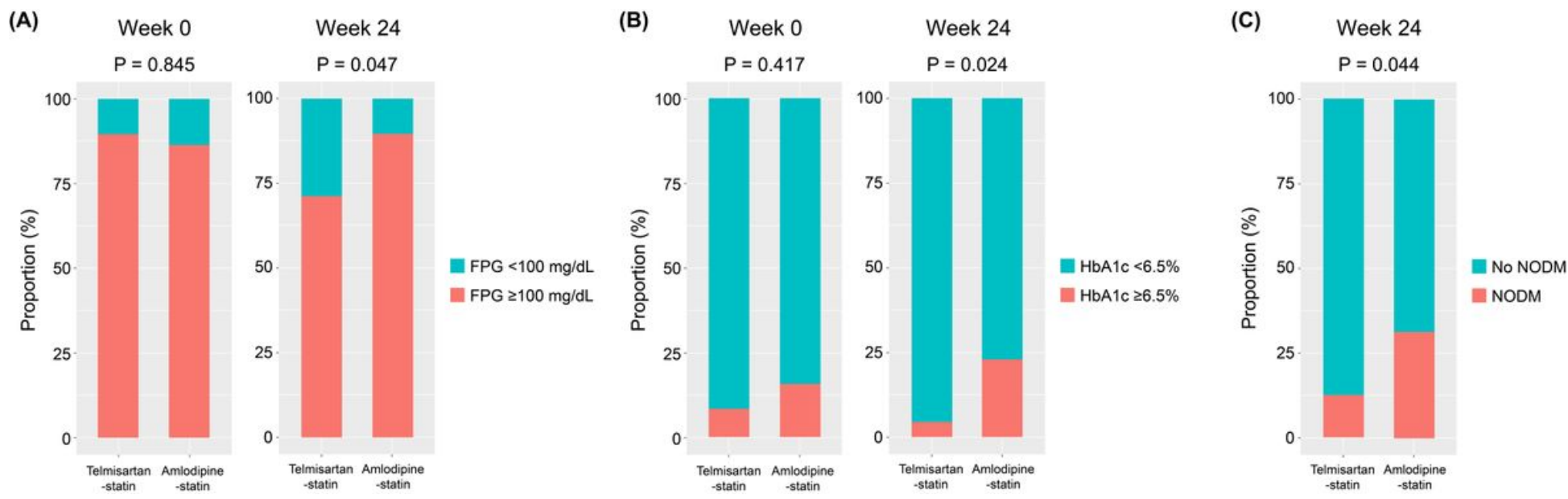

Figure 3

The proportion of participants with fasting plasma glucose $\geq 100 \mathrm{mg} / \mathrm{dL}(\mathrm{A})$ and $\mathrm{HbA} 1 \mathrm{c} \geq 6.5 \%$ (B) at week 0 and week 24 and new-onset DM (C) at week 24. FPG, fasting plasma glucose; NODM, new-onset DM.

\section{Supplementary Files}

This is a list of supplementary files associated with this preprint. Click to download.

- SuppICOMPROMISEver6.0.docx

- SuppICOMPROMISEver6.0.docx 